\title{
Current issues in Scandinavian acute psychiatric wards
}

\author{
TORLEIF RUUD, NILS LINDEFORS, ANNE LINDHARDT
}

\begin{abstract}
The aim of the paper is to provide an overview of some of the most important issues faced by acute inpatient facilities in three Scandinavian countries, including reflections and critical remarks for discussion in this field. Information was drawn from scientific articles and official reports published in recent years, as well as the authors' own knowledge of acute facilities in their home countries. Acute inpatient facilities, including General Hospital Psychiatric Units (GHPUs), in all Scandinavian countries have several issues and problems in common, which include the organisation and capacity of acute services, the assessment of dangerousness and suicidality, the use of coercion and efforts to reduce coercion, the need to define and improve the quality of acute services, and the necessity to improve collaboration and continuity between acute services and other services. Although the emphasis some of these issues receive can vary across the three countries, Scandinavian mental health professionals (and policy makers) have begun to systematically share their experiences in developing a growing spirit of collaboration. Despite the role of welfare state and the deployment of substantial resources in Scandinavian countries, mental health practitioners are struggling to implement best practices in acute wards, to develop differentiated forms of acute services, and to reach the right balance and coordination between acute services and other services.
\end{abstract}

\section{INTRODUCTION}

The aim of this editorial is to provide a brief overview of problems and issues faced by acute inpatient facilities, including General Hospital Psychiatric Units (GHPUs) in Scandinavian countries. The focus is on acute wards for adults, as inpatient services are used much less frequently for adolescents and are primarily substituted with alternative types of care in the case of children. The three Scandinavian countries covered in this paper (e.g., Denmark, Norway, and Sweden) are welfare countries who share a similar geographic Northern Europe location, much of their history and cultural heritage, comparable political situations, and similar health service standards and organization. Denmark and Sweden, however, are members of the European Union, but Norway is not. The population is $\mathbf{5 . 4}$ million in Denmark, 4.6 million in Norway, and 9.1 million in Sweden.

Address for correspondence: Dr. T. Ruud, SINTEF Health Research. Box 124 Blindern, N-0314 Oslo (Norway).

Fax: +47-2206 7909

E-mail: torleif.ruud@sintef.no

Declaration of Interest: there is no conflict of interest for any of the authors.

\section{THE ORGANISATION AND LOCATION OF ACUTE HOSPITAL SERVICES}

Over the last decades, the Scandinavian countries have witnessed a growth in decentralised mental health services and a substantial decrease in the number of psychiatric hospital beds available. Responsibility has been placed on counties for organising the entire range of comprehensive and differentiated mental health services for the population- i.e., from acute wards to community mental health services.

Most Scandinavian acute psychiatric wards are now located in general hospitals that are situated in large cities or towns, but some can be found in new or rebuilt psychiatric hospital wards. In fact, national, county-targeted financial incentives have contributed to investment in new or improved buildings. In Denmark $77 \%$ of hospital patients are housed in single rooms (Regional Statistics, 2006), and these figures are similar in the other two countries. The quality of physical surroundings is usually quite high, but wards in older buildings can be less functional than wards located in newer buildings designed for their current use.

The number of GHPU beds in Denmark ranges between 12 and 25, with an average of 16 beds, and other two countries present fairly similar figures. Most acute departments have one or more acute units available for acute admissions and treatment and sub-acute units for further treatment needs following the most acute phase. Some departments have a specialised emergency unit available to receive all admissions and to assess all patients within one or two days from admission, before 
they are transferred to other units. Variations on these models can be found in all three countries.

The trend in Sweden has been to concentrate emergency wards to fewer locations. Even large cities like Stockholm have only one psychiatric emergency ward available, while local mobile teams are being developed as possibly more cost-efficient alternatives. In some cases, mobile teams and hospitals have also been trying to admit each patient directly to the appropriate type of specialised unit required, obviating the need for a short-term acute ward stay for initial intake and assessment thereby.

In Denmark, security wards, forensic psychiatry, and acute treatment for alcohol and substance abuse all make up part of mental health services, or are organised in relation to them. In Norway, a reform bill enacted in 2004 rendered services for alcohol and substance abuse a division of mental health services. Similarly, security wards and forensic psychiatry are components of mental health services. In Sweden, forensic psychiatry is regionally organized with treatment units located in a few counties, preferably near university clinics, but larger forensic psychiatric hospitals are also available.

The overall number of psychiatric beds for Denmark in 2004 was 6.3 per 10,000 inhabitants, including all types of adult hospital psychiatric units (Regional Statistics, 2006). In Norway, the number of beds was 6.1 per 10,000, including some units for patients with alcohol and substance abuse (Kalseth, 2005). Moreover, there were 4.5 beds per 10,000 in community mental health centres, where inpatients units typically provide services closer to patients' homes and therefore achieving greater continuity of care between outpatient and inpatient services. Some of these mental health centre units are currently functioning as local hospital units, and a few operate as acute wards. Sweden has 4.1 hospital beds per 10,000 , and additional 0.8 beds per 10,000 in forensic wards (2005). The number of hospital beds in Sweden is currently decreasing, due mostly to a reduction in average length of stay rather than to a decrease in number of admissions. Overall, the number of beds in Scandinavian GHPUs is higher than in several other European countries. Yet, the number of hospital beds varies considerably per geographical area in each country. In all three countries, reports with statistics on mental health services are annually produced and used for service monitoring.

It should be noted that no separate statistics on the number of acute beds are currently available for Scandinavian countries, partly because different types of psychiatric wards may also treat acute patients. It is therefore difficult to obtain reliable statistics on the matter.
Separated official figures on the number of beds in GHPUs and in mental hospitals are also similarly unavailable. The reason is that mental hospital wards are mostly organised into psychiatric divisions or departments, and the latter include GHPUs, and statistics are typically reported for entire departments.

Another question relevant to the number of acute beds is whether many patients in acute inpatient services may be treated at a lower level of care with less restriction. A Norwegian census-day study carried out in 2003 estimated that half of the inpatients in acute wards could have been cared for at a lower level of care according to staff judgment (Hagen \& Ruud, 2005). Delay in the availability of other types of residential care is seen as the main reason for this overlooked shift in the locus of care. Better availability of other services and closer collaboration among services could eventually contribute to a reduced need for acute beds.

Many patients admitted to acute psychiatric wards have a problem with substance abuse, and there is growing recognition that the proportion of patients in acute psychiatric wards with alcohol and substance abuse is on the rise. Yet, only $10 \%$ of all psychiatric inpatients covered in a Norwegian national 2003 census-day were reported as having alcohol or substance abuse as one of their diagnose (Gråwe \& Ruud, 2006). Hence, such problems still, to some extent, go underreported. And there is now greater awareness of the need to assess and treat both mental and abuse problems as integrated components of care plans, given that the combination of substance abuse and mental disorders can complicate treatment and increase the risk of violence. Health care and municipal care systems are now collaborating in efforts aimed at improving such treatment. Moreover, national initiatives by the Swedish Ministry of Health, scrutinising quality and safety in current psychiatry in Sweden, have been taken to facilitate these more local-level collaborative initiatives as well as to give users greater voice, helping them play a more active role in the delivery and organization of the services.

In Denmark, concerns have been expressed about the rising number of forensic psychiatric patients and a documented increase in the number (and severity) of criminal acts committed by patients with psychotic disorders (Kramp \& Gabrielsen, 2005).

A national reform bill in Denmark affecting the health sector will reduce the number of health districts from 15 to five by the year 2007 . This transformation will render health districts much larger in administrative terms, much like Norway's regional health trusts. The consequences for mental health services are as yet unknown. 


\section{SYSTEMATIC ASSESSMENT OF DANGEROUSNESS AND SUICIDALITY}

A systematic assessment of dangerousness and suicidality is one core task for acute psychiatric services in their efforts to prevent patients committing serious harm to others or to themselves. This aspect represents just one component of the more general assessment that is required on a routine basis for every patient suffering from a severe disorder. The Norwegian Psychiatric Association has therefore promoted an initiative aimed at developing specific standards for assessing patients admitted to acute wards.

In addition to the much-publicised murder of the Swedish former foreign minister Anna Lind, other violent acts committed by individuals with acute psychotic illness have led to an increased awareness among policy makers of the importance of high quality risk management. Assessment of risk for violence is a difficult task and therefore much attention is now being focused on how to best achieve this aim. Specific rating scales have been developed in Scandinavia for this purpose, and a considerable amount of research is being conducted to fine-tune these assessment instruments. In Denmark, some hospitals are now using National Board of Health guidelines for assessing suicidality, and the issue of developing guidelines for assessing patient dangerousness remains a topic of ongoing discussion.

In Sweden, security inspections have led to requests for better security systems in psychiatric wards. This represents a particularly critical problem not only for forensic psychiatry departments, but also for other types of security wards, due to the risk of fatal incidents, such as homicide and outbreaks of fires initiated by patients.

\section{EFFORTS TO REDUCE COERCION}

The issue of use of coercion is continually debated in Scandinavian countries, and several comparative studies on the topic are currently being conducted (see, e.g., Høyer et al., 2002). Yet, comparative investigation of the use of coercion presents its own inherent difficulties because laws, definitions and reporting procedures vary from country to country. In fact, no comparative statistics adjusted for all the differences and variables that must be considered to produce a reliable comparison are yet available.

A preliminary report from Denmark in 2004 showed that coercion had been used with approximately $20 \%$ of mental hospital ward inpatients - a figure similar to findings from previous years (Use of coercion..., 2006b).
Studies in Norway have also shown fairly stable levels in the use of coercion, notwithstanding successful implementation of the "breaking-though-project" (see below). A recent analysis of data obtained from the above-mentioned Norwegian census-day study showed great geographical variation in the use of coercion and also found that $27 \%$ of compulsory patients were homeless (Helsetilsynet, 2006). The rate of involuntarily admitted inpatients reported in that study was 3 per 10,000 inhabitants, with a range varying from 0.5 to 6.1 across different geographical areas. Another study showed how a different case-mix may account for only part of the geographical variations found in involuntary admissions rates (Bjørngaard \& Heggestad, 2001) and revealed the need to better understand the underlying reasons for these variations if mental health professionals are to effectively reduce the frequency of coercion in their services.

In Sweden, the National Board of Health and Welfare has the task of supervising the use of coercion in psychiatric services. Initiatives have recently been undertaken to reduce the use of coercion and to increase safety by implementing violence risk assessment scales, together with enhanced quality of care and nursing. This phenomenon is particularly relevant in acute wards, given the current trend of bed number reduction. Specifically, bed reduction generally leads to patients suffering more intense morbidity, due to the shorter treatment periods they undergo. These patients may therefore also be at greater risk of violence.

The Norwegian Medical Association is using a "breaking-through-projects" model to place emphasis on the aspects of health services that most urgenty require transformation. During a use-of-coercion project (implemented several years ago) many participating acute wards succeeded in reducing their rates in use of coercion by maintaining increased awareness and focus on the issue over a period of time (Mathisen \& Føyn, 2002). In Denmark, a similar project based on the Norwegian model has also been conducted.

Following the murder of Sweden's former foreign minister, awareness of improvement in psychiatric care has increased considerably in this country. The possibility of allowing for coercion in out-patient treatment without mandatory hospital treatment is being currently considered, mainly to facilitate continuous pharmacological treatment and to reduce relapse risk. In Norway, a new law went into effect in 2000 , which authorised mental health professionals to also use coercion in outpatient treatment. Yet the regulation has thus far been applied very rarely, and sufficient data concerning its overall utilization and consequences are still not available. 
Moreover, as in Sweden, there is as an ongoing debate in Denmark concerning a new law that would allow for coercion outside inpatient units. Yet, many psychiatrists have expressed scepticism about the proposed new law, fearing that it will lead to an undesirable change in the current clear definitions sanctioning the use of coercion only with persons suffering from psychotic disorders.

\section{DEVELOPING DIFFERENTIATED ALTERNATIVES TO ACUTE WARDS}

Scandinavian health authorities are searching for alternatives to acute wards, and the Norwegian Minister of Health has instructed the country's health trusts to establish mobile acute teams in all community mental health centres by the year 2008 (Gråwe \& Ruud, 2005). This decision was based on positive experiences accrued in the UK with a similar model, and guidelines for organising this type of acute teams in Norway are now being developed.

Similar developments are unfolding in Denmark and Sweden. Mobile crisis teams are being set up, with the overall aim of securing continuity of care and diminishing the use of coercion. This development is in an early phase in all three Scandinavian countries, and it will take years to have these teams in full operation throughout Scandinavia.

Another alternative to acute wards, used in Norway, is represented by the setting up of low threshold inpatient units or by the addition of acute beds at community mental health centres. The partition of tasks between hospitals and these centres, also regarding the treatment of acute patients, has been the subject of discussion by the Norwegian health authorities throughout the last year. This issue will be addressed in guidelines to be published in 2006.

\section{IMPROVING THE QUALITY OF TREATMENT IN ACUTE WARDS}

Several initiatives aimed at generally improving the overall architecture of mental health services in Scandinavia will also have a positive influence on the quality of acute psychiatric services there. One such initiative is represented by the development of evidencebased clinical guidelines targeted to the main diagnostic groups - guidelines that may improve patient intake and assessment and are considered a prerequisite for improving and standardising patient care.
Acute treatment itself, however, also greatly needs to be improved. Acute wards may easily be dominated by use of medication and restraints to control patients' behaviour and to keep inpatient stays as brief as possible. Yet, questions regarding different treatment goals and psychosocial aspects of acute treatment have also been raised, and many clinicians feel that these are important aspects that must be dealt with. It is interesting to note that these issues seem to have received greater attention from nurses and other professionals working in ward milieus than by psychiatrists and psychologists (Hummelvoll \& Severinsson, 2001).

In Norway, an annual multidisciplinary conference called the "Forum for acute psychiatry" is now bringing together a large number of clinicians and milieu therapists from acute wards and teams, with the aim of improving the quality of acute treatment. This event has shown the generally felt need for regular meetings allowing mental health professionals to share their experiences and learn from others to improve the quality of their services.

Acute inpatient wards in Norway have been under the scrutiny of mass media several times over the last few years, due severe, negative events such as homicides by or suicides of psychiatric patients. The most well known event occurred when a patient, who had recently discharged from an acute ward in Oslo, attacked people on a tram, killing one person and seriously injuring four others. After this tragic accident, a consulting firm was engaged to carry out an in-depth evaluation and draft a report on the functioning of that department. Revisions of procedures and practice were later implemented at the hospital, based on report recommendations, and this document was also read with interest by administrators working in other acute facilities.

Yet improvement of Scandinavia's acute psychiatric services cannot be achieved by addressing only problems within the acute wards or services themselves. The quality and accessibility of other mental health services and primary health care are crucial factors in determining how many patients will be referred to acute facilities. Moreover, the continuity of care for patients discharged from acute wards to further treatment outpatient clinics is frequently unsatisfactory - a criticism that was raised by the Norwegian Board of Health in a report based on the inspection of many acute facilities and outpatient clinics

Moreover, an increasing proportion of the Scandinavian population come from different ethnic backgrounds, especially in certain geographical areas. The extent to which acute psychiatric facilities and other psychiatric services are able to provide adequate assessment and care for minority group members has yet to be ascertained. In 
one Norwegian study, immigrants were not overrepresented in an acute ward, as compared with native Norwegian in-patients, but they did suffer from more severe psychoses and received more frequently coercive interventions (Berg \& Johnsen, 2004) - a finding that may indicate greater difficulty for ethnic minority members in obtaining early interventions than for their native Norwegian counterparts.

The results from a multi-centre study of acute psychiatry conducted in Norway will be presented in 2006. Most of the country's acute wards and mobile acute teams are participating in this study examining the clinical course of more than 4,000 admitted patients and the acute services they receive. The research design was originally developed in a network for acute services supported by the Norwegian Directorate for Health and Social Affairs. As clinicians working in acute facilities have been involved in the conception and development of this study, the study itself will represent an important occasion/opportunity for contributing to the improvement of mental health services by stimulating critical reflection on clinical practice.

\section{CONCLUSION: WE STILL NEED TO FOCUS ON ACUTE SERVICES}

The first conference of European health ministers focusing exclusively on mental health was held in Helsinki in January 2005. The declaration and action plan stemming from that meeting placed a great deal of emphasis on community psychiatry, primary care, reduction of stigma, health promotion and prevention, and user involvement by users and relatives. Acute hospital services were however only briefly mentioned. Yet, acute inpatient facilities represent a key component of the overall network of mental health services and therefore still require our attention and our efforts to improve them.

Despite the availability of an efficient welfare state and the deployment of a substantial amount of health resources in Scandinavian countries, mental health service providers are struggling to implement best practices in acute inpatient facilities, to develop differentiated forms of acute services, and to achieve the right balance and coordination between acute inpatient services and other services. Hence, there is still a great need for user involvement, development of higher standards of care, and further research if we are to bring about essential improvement in acute services.

\section{REFERENCES}

Berg J.E. \& Johnsen E. (2004). [Are immigrants admitted to emergency psychiatric departments more often than ethnic Norwegians?]. Tidsskr. Nor Laegeforen. 124 (5), 634-636.

Bjørngaard J. \& Heggestad T. (2001). [Can case-mix explain differences in involuntary admissions to Norwegian psychiatric hospitals?] Kan ulik pasientsammensetning forklare forskjeller i tvangsinnleggelser? Tidsskr. Nor Laegeforen. 121 (29), 3369-3374.

Grăwe R. \& Ruud T. (2005). [Alternative acute services in mental health services for adults] Alternative akuttilbud i psykisk helsevern for voksne. Tidsskr. Nor Laegeforen. 125 (23), $3265-3268$.

Gråwe R. \& Ruud T. (2006). [Substance abuse and mental disorders in mental health services for adults] Rus og psykiske lidelser i psykisk helsevern for voksne. SINTEF rapport STF78 A06003. SINTEF Helse: Trondheim/Oslo.

Hagen H. \& Ruud T. (2005). [Inpatients in mental health services for adults November 20th 2003] Pasienter i psykisk helsevern for voksne 20 november 2003. SINTEF Rapport STF78 A045026. SINTEF Helse: Trondheim.

Helsetilsynet (2006). [Use of coercion in the metnal health services] Bruk av tvang i psykisk helsevern. Oslo, [Norwegian Board of Health] Heisetilsynet. Ref Type: Pamphlet.

Høyer G., Kjellin L., Engberg M., Kaltiala-Heino R., Nilstun T., Sigusjonsdottir M. \& Syse A. (2002). Paternalism and autonomy: A presentation of a Nordic study on the use of coercion in the mental heal th care system. International Joumal of Law Psychiatry 25, 93-108.

Hummelvoll J. \& Severinsson E. (2001). Coping with everyday reality: Mental health professionals' reflections on the care provided in an acute psychiatric ward, Australian and New Zealand Journal of Mental Health Nursing 10, 156-166.

Kalseth J. E. (2005). [Samdata Mental Health Services. Report for 2004. Comparative data on the mental health services.] Samdata psykisk helsevern. Sektorrapport 2004. Sammenligningsdata for psykisk helsevern. SINTEF Report 2/05. SINTEF Helse: Trondheim.

Kramp P. \& Gabrielsen G. (2005). [Forensic patients - development 2000-2004] Retspsykiatriske pasienter-udvikling 2000-2004. Ugeskr. Laeger 167(47), 4469-4472.

Mathisen J. \& Føyn P.R. (2002). [Use of coercion. Report from the breaking-through-project in psychiatry] Bruk av tvang. Rapport fra Gjennombruddsprosjekt psykiatri. [Norwegian Medical Association] Den norske legeforeningen: Oslo. Ref Type: Pamphlet

[Regional statistics] (2006). Amtrådsforeningens statistikbase. Amtrådsforeningen, Denmark . Internet Communication.

[Report on the health services 2005] (2005). Hälso- och sjukvårdsrapport 2005. Socialstyrelsen: Stockholm.

[Use of coercion in mental health services 2004 (preliminary figures)] (2006). Andendelsen af tvang i psykiatrien 2004 (foreløbige tall). Copenhagen, Nye tall fra Sunhedsstyrelsen 2005:18 [New figures from the National Board of Health 2005:18]. 